\title{
QUALITY IMPROVEMENT IN MANUAL ASSEMBLY BY SOFTWARE-BASED EVALUATION OF HUMAN MISCONDUCT
}

\author{
M. Sc. Lena Blackert \\ Department of Quality and Process Management, University of Kassel, Germany. E-Mail: blackert@uni-kassel.de \\ Dipl.-Logist. Christian Kern \\ Department of Quality Management, RIF Institute for Research and Transfer, Germany. E-Mail: \\ Christian.kern@rif-ev.de \\ Prof. Dr.-Ing. Robert Refflinghaus \\ Department of Quality and Process Management, University of Kassel, Germany.E-Mail: refflinghaus@uni- \\ kassel.de \\ M. Sc. Tim Trostmann \\ Department of Quality and Process Management, University of Kassel, Germany.E-Mail: trostmann@uni- \\ kassel.de
}

For reaching a level of high quality, production processes must be carried out both, economically and reliably. Despite automation and digitalization, manual assembly operations still constitute a key element for creating efficient production processes. However, in practice, creating robust and efficient manual assembly processes often fails because the occurrence of human errors cannot be quantified prospectively. Therefore, a corresponding procedure has been developed at the institutes of the authors. The module-based method "Methods Time and Quality Measurement" (MTQM) utilizes human error prediction techniques on the basis of Performance Shaping Factors (PSF) to determine human error probability values. It enables the user to perform a prospective evaluation of manual assembly processes, to identify critical assembly steps and to assess the resulting risk monetarily. This paper explains the conception and the development of the MTQM method. Additionally, it outlines the motives and development steps regarding the creation of a MTQM software tool. The paper clarifies how the resulting MTQM app not only reduces the necessary knowledge and implementation effort of MTQM, but also increases the reproducibility and prediction accuracy of the method. In this context, the paper illustrates the development of standardized translations of MTM-UAS building blocks with MTQM standard words. Additionally, it outlines an approach to optimize the subjective assessment of PSFs, especially regarding ergonomic influences on human failure.

Keywords: Human Reliability Assessment, forecast, manual assembly operations, time and quality measurement, process optimization, ergonomic influences, Performance Shaping Factors, computer aided evaluation.

\section{Introduction}

Currently, the change from seller to buyer markets and the connected demand for customer specific products and flexible production processes represent major challenges for manufacturers (Jochem 2010; Neuhaus 2018). In order to tackle these challenges all eyes are set to Industry 4.0 and corresponding topics such as automation, digitalization and interconnectedness. However, the economic use of automated assembly processes is reduced when concerning high product diversities, small production quantities and short product life cycles. More specifically, the amortization period of the necessary operating resources can often not be achieved and the residual capital value cannot be amortised (Lotter and Müller 2018). Therefore, despite automation and digitalization, the area of manual assembly and the characteristics of human activities remain important (Kuhlang et al. 2015; Wiendahl et al. 2015).

Manual assembly processes are the endmost production process. Therefore, they can be qualified as a melting pot for organizational and qualitative errors caused in previous processes (Brecher and Schapp 2009). Human activities contribute to this issue as they are always subject to an error probability (Graf Hoyos 1992; Glendon et al. 2006) leading to rework, rejects and delayed work processes (Zülch et al. 1998). A vast number of factors, so called Performance Shaping Factors (PSF), influence the extent of this

Proceedings of the 29th European Safety and Reliability Conference.

Edited by Michael Beer and Enrico Zio

Copyright (c) 2019 European Safety and Reliability Association.

Published by Research Publishing, Singapore.

ISBN: 978-981-1 1-2724-3; doi:10.3850/978-981-11-2724-3_1041-cd 


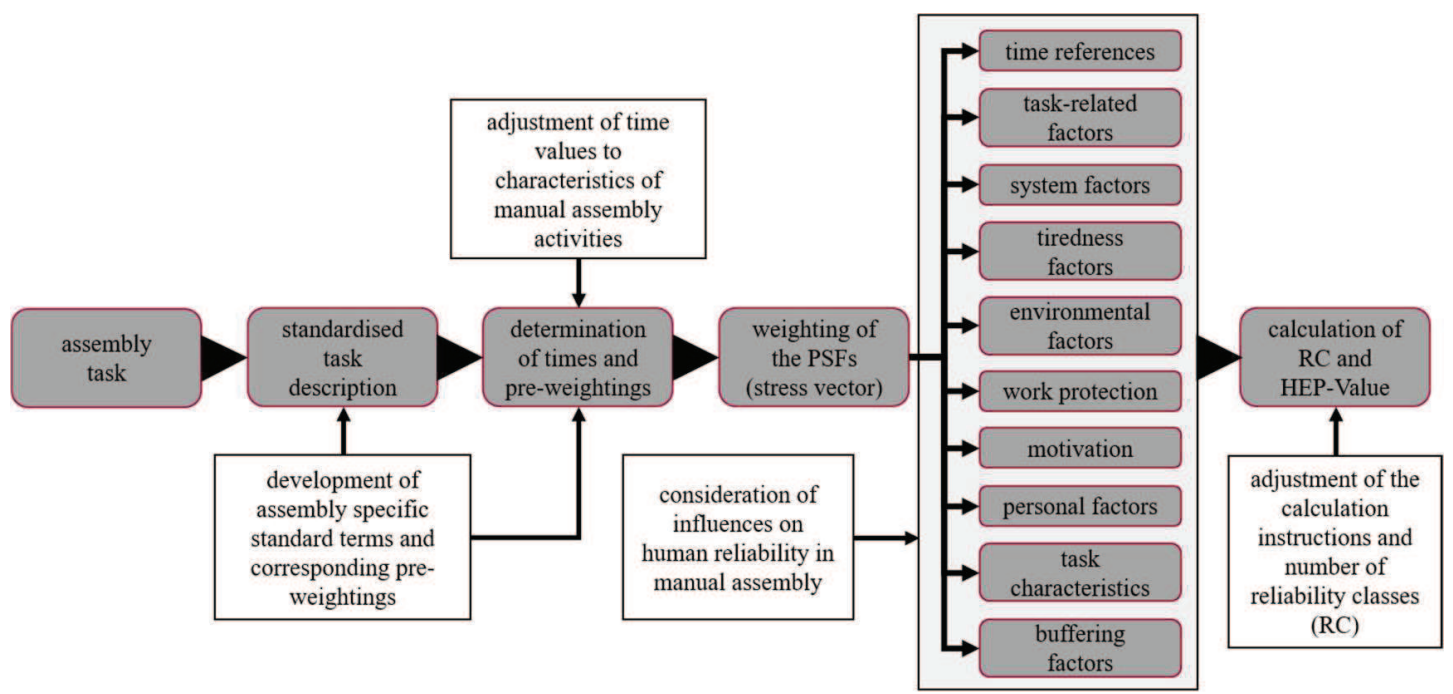

Fig. 1. Procedure of the MTQM reliability analysis and assembly-related adjustments based on (Kern and Refflinghaus 2014)

human error probability (HEP). Among these factors are e.g. psychological influences or ergonomic influences on human reliability (VDI 2015; Swain and Guttmann 1983). Accordingly, the HEP is directly connected to the stability and capability of the corresponding processes (Kern and Refflinghaus 2017). Without adequate measures to prevent human errors, critical assembly steps have to be discovered and rectified during the production process leading to high quality-related costs (Kern and Refflinghaus 2017). Thus, an appropriate preventive quality planning of manual assembly processes is of major concern for organizations regarding customer satisfaction and organizational success. When planning and optimizing manual assembly processes, however, the focus is usually only on the time required for the corresponding task (Lotter and Wiendahl 2006). One of the reasons for this is the fact that none of the HRA (Human Reliability Assessment) methods currently available focus on the identification of the related error causes (Löwe 2007) and the area of manual assembly. Because of this, the systematic assembly planning method MTQM (Methods Time and Quality Measurement) has been developed at the RIF e.V. in cooperation with several industry partners. With the help of MTQM, manual assembly processes in series production can be analyzed prospectively during the planning phase of a manual assembly system considering both, time as well as quality relevant aspects (Kern and Refflinghaus 2015).

\section{The development of the MTQM method}

In the course of time several HRA methods have been developed for a variety of application purposes. An overview of current HRA methods can be found in VDI 4006 part 2 as well as in Bell and Holroyd (2009). They can be categorized in task-related (PSF-based) and situation-related methods (VDI 2017). As to the typical characteristics of series production, PSF-based methods are principally suitable for the field of manual assembly. These methods address the assessment of processes in which the worker knows the characteristics of the task and the sequence of activities well (VDI 2017). Among the PSF-based methods is the Expert System for Task Taxonomy (ESAT). Although Brauser developed the method initially for the assessment of tasks in safety critical areas such as power plants, he argues that it should principally be suitable for the assessment of any task conducted in a work system (Brauser 1990). The method is characterized by the setup of a detailed task description and the assessment of relevant PSFs (Brauser 1990). Consequently, when trying to apply it in the context of manual assembly, it became clear that neither the standard terms nor the considered PSFs were sufficient to describe these processes comprehensively (Kern 2016a). In order to enable an adequate application in the field of manual assembly, several adjustments were necessary while maintaining the basic structure of the method. The procedure of the MTQM method is shown in figure 1, depicting the 
aspects which had to be adjusted. The first issue addresses the setup of a standardized task description. Thereby, the assembly process is determined consistently regarding cognitive and coordinative tasks, elements to be handled and frequencies of actions. To achieve this, the task has to be structured into motion sequences consisting of task elements. These task elements are then described with the help of so-called standard words taken from the ESAT database (Brauser 1990). However, the standard terms of the ESAT method were not sufficient for an adequate description of manual assembly processes. Consequently, about 45 assembly specific terms were defined (e.g. tighten und loosen, slide, separate, etc.) (Kern and Refflinghaus 2015). The final objective of the detailed task description is the assignment of time values and pre-weightings to each of the standard words used within it. This is done in the second step of the ESAT method, which directly led to further necessary adjustments. The preweightings with a value range between 1 and 10 represent the relative difficulty of the standard words, respectively the contribution of each standard word to the overall difficulty of the task (Brauser 1990). These pre-weightings were developed in the course of empirical research studies and are unique for each standard word. This is why new pre-weightings had to be developed for each of the newly created standard words. Therefore, expert interviews combined with pairwise comparisons based on a standardized list of criteria were conducted (Kern and Refflinghaus 2012). In addition to preweightings, the new standard words also required time values. Furthermore, the time values of ESAT refer to rarely carried out control and monitoring activities. Because of this, they did not match the characteristics of manual assembly tasks in series production (Kern and Refflinghaus 2017). In order to tackle both of these issues, time values resulting from the building block system MTM-UAS (Methods-Time Measure-mentUniversal Analysing System) were used to adjust already existing time values as well as to define time values for new standard words. Here, MTMUAS was chosen as the primary method of choice because, on the one hand, it is an acknowledged standard directly addressing the area of manual assembly in series production (Deuse and Busch 2012). On the other hand, it has the same degree of compaction as the motion sequences of ESAT (Kern and Refflinghaus 2012). In order to adjust already existing time values, the following procedure was added to the reliability analysis: Each task is additionally analyzed with MTMUAS so that the time values of the created task elements and motion sequences of the ESAT analysis can be compared to those of the corresponding MTM-UAS action elements. The central objective is to keep the corresponding ratio. Accordingly, the MTM-specific time value of each standard word can be calculated via Eq. (1) (Kern and Refflinghaus 2016a):

$$
\begin{aligned}
& \frac{\text { new time value }(\text { standard word) }}{\text { time value UAS action element }} \\
= & \frac{\text { old time value (standard word) }}{\text { time value ESAT motion sequence }}
\end{aligned}
$$

Because of the time adjustment, the ESATspecific pre-weightings had to be adjusted as well. The adjusted time values tended to be much lower than the initial ESAT values due to learning effects and task repetition in series production. Consequently, the worker has less time to carry out the corresponding task so that the preweighting is expected to be higher. Because of this, the pre-weightings are adjusted by increasing their value in the same ratio as the time values have decreased. A summarizing example of the necessary adjustments regarding time values and pre-weightings is shown in figure 2. Here a movement sequence of an assembly process consisting of three task elements is shown in which the worker has to assemble an instantaneous water heater. After the standardized task description has been created, the different PSFs have to be evaluated. The PSFs are summarized within the stress vector and have to be rated with a value between zero (no influence) and one (high influence).

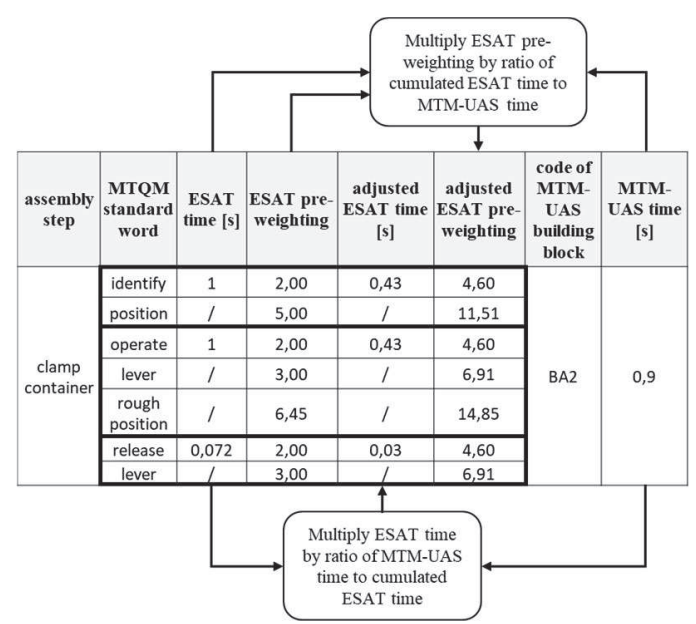

Fig. 2 Example of the assembly specific adjustment of ESAT standard words (own elaboration)

Typical factors related to the human error probability are according to Brauser (1990) and the ESAT method: 
- $\quad$ S1: task type (simultaneity of activities)

- S2: task characteristics (e.g. complexity or difficulty)

- S3: personal factors (e.g. experience or motivation)

- S4: environmental factors (e.g. as climate or noise)

- S5: system-related factors (e.g. technical reliability or time pressure)

Altogether 29 PSFs are considered within the ESAT method, which have to be assessed mostly subjectively, respectively on the basis of expert interviews. However, practical applications of the ESAT method in the field of manual assembly showed that the 29 PSFs did not consider all relevant factors influencing the worker during manual assembly activities. Therefore, assembly specific PSFs were derived from several HRA and predetermined motion time systems resulting in the development of an assembly specific stress vector (Kern and Refflinghaus 2016a). Among these new PSFs are e.g. ergonomic aspects or the suitability of used tools. With all the PSFs assessed, finally the HEP (human error probability) can be calculated after classifying the task into one of ten reliability classes (RC). The corresponding calculation model is given in (Brauser 1990). Due to the increased number of PSFs, the calculation model had to be adjusted by compensating this issue with the help of an assembly-specific pre-factor (Kern and Refflinghaus 2015). Additionally, activities in manual assembly have a much lower error probability than the cognitive activities considered within ESAT. Hence, the lowest RC was subdivided into ten further classes in order to enable an appropriate comparison of assembly processes (Kern and Refflinghaus 2016a). With all the adjustments considered, applications in industry have shown that MTQM enables the quality engineer or work planer to identify critical assembly steps and to predict corresponding failure rates. By combining this information with the associated failure costs the identified risk can even be quantified monetarily (Kern and Refflinghaus 2014).

\section{Software-based evaluation of human misconduct}

Despite its applicability in principle, MTQM still required a high knowledge regarding predetermined motion time systems and HRA methods. Furthermore, the setup of the standardized task description took a lot of time. These issues can be seen as primary factors influencing the dissemination of the method in industry. In order to reduce the implementation effort and the necessary knowledge, efforts were made to implement it into an easy to use, excelbased software tool. Due to the issues mentioned before, the first objective was to simplify the creation of the task description. Accordingly, the basic procedure of MTQM and the MTQM database, were mapped in the software tool (Kern and Refflinghaus 2016b). Furthermore, the standard words, time values and pre-weightings in the database were analyzed regarding similarities in order to form standardized analysis modules. As a result, the user was able to create the standardized task description by a simple "drag\&drop" procedure regarding modules and standard words, in which the corresponding time values and pre-weightings were derived from the database automatically (Kern and Refflinghaus 2016b). The second objective regarding the development of the MTQM software tool was the integration of the stress vector and the calculation model as well as the development of an intuitive user interface with the help of a Kano project (Kern and Refflinghaus 2018). As a result, e.g. continuously adjustable slide controllers for the assessment of each PSF were added to the tool. Furthermore, a summarizing overview of the relevant outcomes of the analysis was created, which includes e.g. graphs visualizing the difficulty of each assembly step. After adding the calculation rules to the software tool, it was finally possible to calculate HEP values by software. Thereby, a means to guide the user through the reliability analysis of an MTQM analyses was created offering him the necessary assistance regarding HRA knowledge.

\section{On the road to a higher reproducibility}

However, one issue, which was still not considered adequately within the software, is the consideration of assembly specific time values based on MTM-UAS and the adjustment of preweightings. Moreover, despite the new software tool, there was still the problem of a low reproducibility of the MTQM method. This low reproducibility on the hand resulted from the vague ESAT syntax and the issue that often more than one ESAT standard word was principally suitable to describe a given task adequately (Kern and Refflinghaus 2013). This led to different standardized task descriptions for a given task which have been created by different users. On the other hand, the subjective assessment of PSFs 
via expert interviews is a critical problem in HRA methods that also influences reproducibility and accuracy (Lolling 2003; Mosleh and Chang 2004). The challenge to solve these issues represented the third objective of the software tool development resulting in the creation of the MTQM app (see figure 4).

In order to achieve this objective, two fundamental approaches were used. The first approach resulted from a detailed analysis of already conducted MTQM analyses and the MTQM database. Thereby, it became clear that it is possible to translate MTM-UAS building blocks with MTQM standard words. Due to this, it was analyzed, how far an MTQM task description can be derived from a given MTMUAS analysis. Consequently, standardized translations of every relevant MTM-UAS building block were developed by analyzing the basis and rules of the MTM-UAS system. The critical issue, which had to be considered when translating the building blocks, was that it is not possible to derive all the information, which is necessary for the ESAT standard language, from the MTM-UAS building blocks. This becomes clear when looking at figure 3 depicting a part of the translation of the MTM-UAS building block "operate".

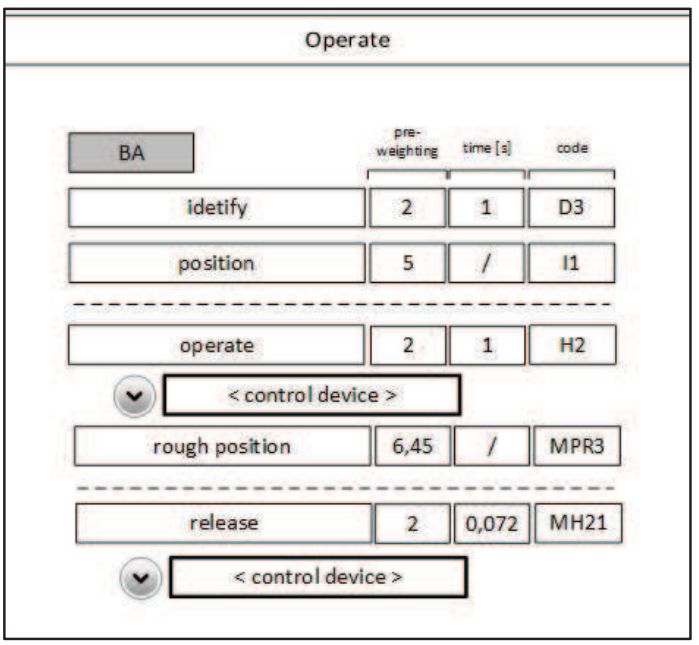

Fig. 3. Example of a translated MTM-UAS building block (own elaboration)

In the ESA'I standard language, it is ditferentiated between controlling a button, switch or lever. As it is not possible to derive this information clearly from the corresponding MTM-UAS building block, it has to be specified separately. Accordingly, if an MTM-UAS analysis persists, only this aspect has to be determined instead of seven standard words in order to derive the corresponding motion sequence of the ESAT standard language. This represents a first step on the way to a higher reproducibility of MTQM.

The issue regarding the adjustment of time values was solved by considering the procedure mentioned in the description of MTQM. The necessary time values of the MTM-UAS building blocks can be derived from the corresponding MTM-UAS analysis and MTM-UAS datasheets. Regarding the adjustment of the pre-weightings it became clear during the analysis of the MTQM database that the adjustment in some cases can either lead to a change of the ratio between some words or to values which are much higher than ten. Accordingly, the adjustment is not in line with the basic concept of the ESAT method. Furthermore, MTM time values are based on the MTM standard performance. This means that they are meant to describe a performance which a person of average ability can perform permanently without work fatigue (German MTM Association 2003). Consequently, the adjustment of pre-weightings is not considered anymore. How far this influences the basic calculation model of the MTQM method is currently further investigated.

Within the second approach regarding the optimization of reproducibility, the subjective assessment of PSFs within the stress vector was focused. More precisely, it was investigated how far critical influences on human reliability resulting from the area of physical strain can be derived from contemporary ergonomics-related assessment methods. This area was chosen as there are several generally acknowledged assessment methods and standards available dealing with this issue (Kern et al. 2018). Relevant aspects of physical strain regarding the area of manual assembly are body postures/movements, load handling, action forces and repetitive activities of the hand-arm area, which can occur in combination (Fransson-Hall et al. 1996; Lotter et al. (2012)). Contemporary methods considering these aspects are the Key Indicator Method Manual Handling Operations (LMM $\mathrm{mA}$ ) and the Ergonomic Assembly Worksheet (EAWS) (Lins and Britzke 2010). However, the LMM mA does not consider a combined assessment of different activities with different loads, body postures etc. (Steinberg 2012). Therefore, the EAWS is the method of choice when assessing manual assembly operations (Heidl et al. 2018). Besides the basic aspects of physical strain, namely repetition and physical fatigue, six additional PSFs have been identified which can be derived from an EAWS analysis. Thus, the output of an EAWS analysis 


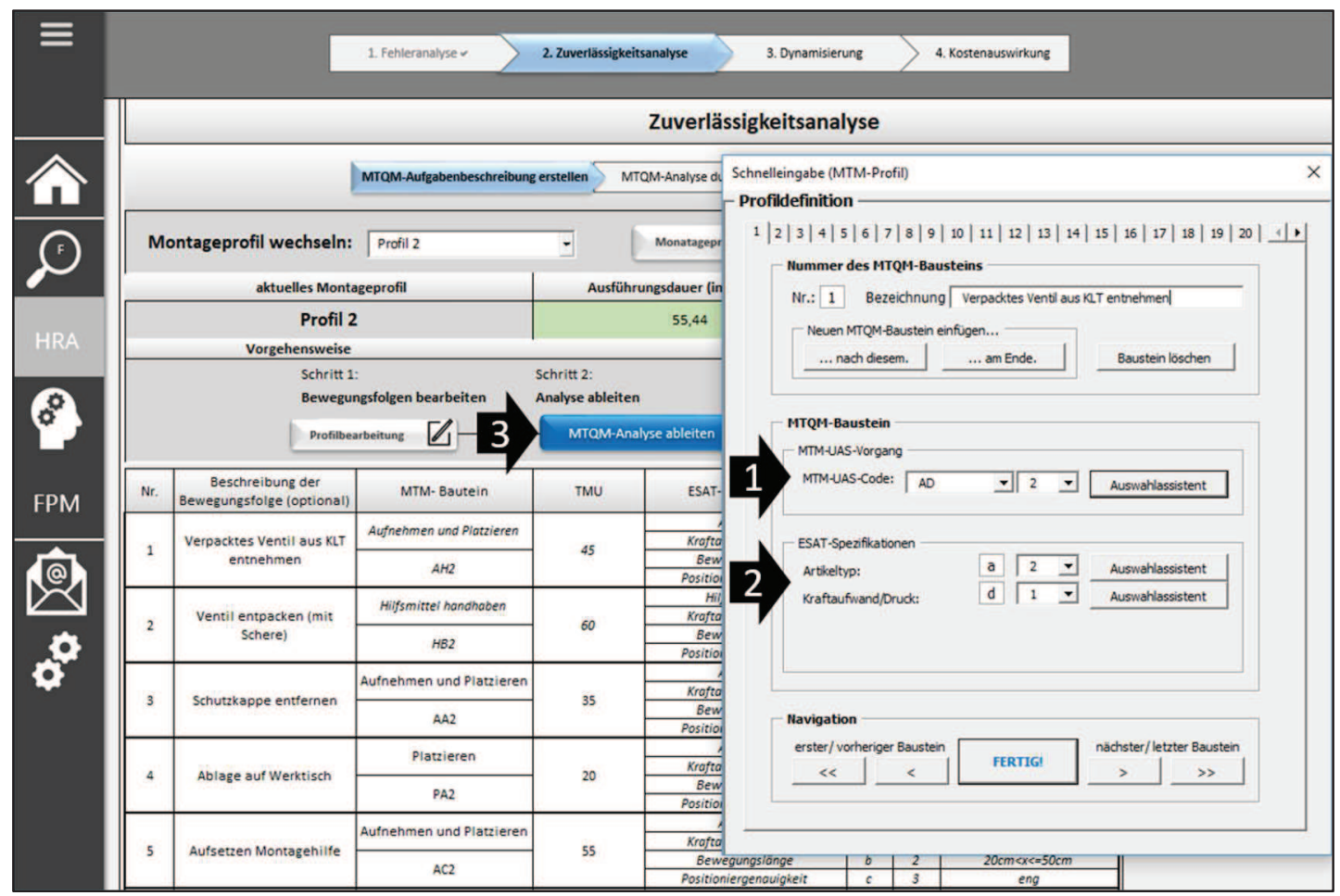

Fig. 4. The MTQM app (own elaboration)

can be used principally to assess ergonomicsrelated PSFs more validly and thereby improve the reproducibility of MTQM.

\section{The MTQM app - Software-based evaluation of human misconduct 2.0}

As a result, it is now possible to derive nearly a complete MTQM task description from a MTMUAS analysis. Accordingly, the basic procedure of the MTQM software tool has been revised and redesigned. As shown in figure 4 the newly developed MTQM app now begins with the determination of the relevant MTM-UAS building blocks (arrow 1). The corresponding MTM-UAS-Code can either be entered directly or via the relevant MTM data sheets, which can be called up by clicking on the assistant button. Next, the ESAT-specific information has to be entered in a similar way, either by code or by using the assistant. The latter gives detailed explanations regarding the definition and the characteristics of the relevant aspects. In the depicted case a variant of the MTM-UAS building block "pick and place" has been selected. When using this building block, extra information is necessary concerning the type of article having to be handled and the force needed to place it at, respectively in the desired destination. After the whole MTM-UAS analysis has been entered into the tool by following this procedure, the MTQM analysis can finally be derived by simply clicking on the corresponding button (arrow 3). The next step is the assessment of the stress vector and finally the calculation of the HEP value. A way to integrate the approach regarding ergonomicsrelated PSFs into MTQM is currently being investigated.

\section{Summary and Outlook}

With the help of the standardized building block translations it is now possible to derive an MTQM analysis directly from a given MTM-UAS analysis by adding just a few information. Thereby, it is set that only the standard words determined in the translation are used to describe the corresponding motion sequence. As the MTM system possesses a clearer and better defined syntax than the ESAT language, created process descriptions are more consistent. Consequently, this leads to a much higher reproducibility and an even lower implementation effort of the MTQM 
method. Following this development, the basic structure of the MTQM software tool has been improved. Additionally, the tool has been modernized so that it now follows a contemporary app design increasing usability. Furthermore, it has been outlined that with the help of the EAWS method ergonomic PSFs can be assessed more systematically and comprehensibly. Future development addresses research regarding the optimization of the calculation model due to the omission of adjusted pre-weightings and the improvement of the PSF assessment. Current approaches in this regard are e.g. the introduction of a variable pre-factor for the PSFs which are assessed subjectively. Furthermore, user interviews are currently carried out in order to identify the potential of sounder PSF descriptions and slide controllers with different subdivisions of scaling.

\section{References}

Bell, Julie and J. Holroyd (2009). Review of human reliability assessment methods. Prepared by the Health and Safety Laboratory for the Health and Safety Executive 2009. Research Report 679. http://www.hse.gov.uk/research/rrpdf/rr679. pdf.

Brauser, K. (1990). Aufgabentaxonomie - Ein Verfahren zur Ermittlung der menschlichen Leistung bei der Durchführung von Aufgaben. Messerschmidt-Bölkow-Blohm, Ottobrunn.

Brecher C. and L. Schapp (2009). Strategien und Trends in der Montagetechnik und organisation. Apprimus, Aachen.

Deuse J. and F. Busch (2012). Zeitwirtschaft in der Montage. In: B. Lotter and H.-P. Wiendahl (Eds.), Montage in der industriellen Produktion. Ein Handbuch für die Praxis, pp. 79-107. Springer, Berlin, Heidelberg.

German MTM Assoziation (2003). Lehrgangsunterlage, Part 1, MTM Grundverfahren. n.n., Hamburg.

Glendon, A. I., Sharon G. Clarke, and E. F. Mckenna (2006). Human Safety and Risk Management. CRC Press, Hoboken.

Graf Hoyos, C. (1992). Die Zuverlässigkeit des Menschen. Risiken und Chancen. In: H. Bubb and S. Albers (Eds.), Menschliche Zuverlässigkeit Definitionen, Zusammenhänge, Bewertung, pp. 11-15. ecomedStorck, Landsberg am Lech.

Fransson-Hall, C., S. Bystrm, and A. Kilbom (1996). Characteristics of forearm-hand exposure in relation to symptoms among automobile assembly line workers. Am. J. Ind. Med. 29. 15-22.
Heidl, M-J., A. Boespflug, and J. Wakula (2018). Evaluierung von fünf ScreeningBewertungsverfahren für repetitive physische Belastungen anhand des subjektiven Belastungsempfindens der Arbeitspersonen in der Montage der Automobil-Zulieferindustrie. In: Zeitschrift für Arbeitswissenschaft 72, pp 120-129.

Jochem, R. (2010). Was kostet Qualität? Wirtschaftlichkeit von Qualität ermitteln. Hanser, Munich.

Kern, C. and R. Refflinghaus (2016a). Modification of the HRA-method ESAT for improving human reliability in manual assembly. In Proceedings of the ESRELConference. Conference on European Safety and Reliability. Glasgow, UK.

Kern, C. and R. Refflinghaus (2015). Expert System for Evaluating Human Reliability in Manual Assembly Operations. In Proceedings of the 18th International Conference on Quality and Service Science. Toulon-Verona-Conference.

Kern, C. and R. Refflinghaus (2014). Prospektive Ermittlung und Reduzierung potenzieller Fehler für manuelle Montagelinien. In: S. Gröger, T. Eiselt and J. Schuldt (Eds.), Qualitätsmanagement denken - motivieren leben, pp. 67-92. Shaker, Chemnitz.

Kern, C. and R. Refflinghaus (2012). Interdisziplinärer Ansatz zur Vorhersage und Reduzierung menschlicher Fehlerwahrscheinlichkeiten in der manuellen Montage. In R. Woll and M. Uhlemann (Eds.), Berichte zum Quaitätsmanagement. Vielfalt Qualität - Tendenzen im Qualitätsmanagement, pp. 19-14. Shaker, Aachen.

Kern, C. and R. Refflinghaus (2013). Crossdisciplinary method for predicting and reducing human error probabilities in manual assembly operations. Total Quality Management and Business Excellence 24(78), 847-858.

Kern, C. and R. Refflinghaus (2016b). Process optimization in manual assembly by software-based identification of qualitycritical work steps. In Proceedings of the 19th International Conference on Quality and Service Science. Toulon-Verona-Conference.

Kern, C. and R. Refflinghaus (2018). Adapting Kano's Theory for weighting and implementing customers requirements on a software tool for assessing human reliability in manual assembly. International Journal for Quality Research 12(4), 835-850. 
Kern, C. and R. Refflinghaus (2017). On the track of human errors - Procedure and results of an innovative assembly planning method. In Proceedings of the 15th Global Conference on Sustainable Manufacturing, Haifa, Israel

Kern, C., R. Refflinghaus, and T. Trostmann (2018). Preventive quality improvement by ergonomic design of manual assembly operations. In Croatian Ergonomics Society (Eds.), Ergonomics 2018 - Emphasis on Wellbeing. Proceedings of the 7th International Ergonomic Conference., Zagrep, Croatia.

Kuhlang, P., T. Finsterbusch, T. Mühlbradt, and S. Liebig. (2015). Produktive und ergonomische Arbeit in der Industrie 4.0Ganzheitliche Planung und Gestaltung menschlicher Arbeit, pp. 11-15, MTMInstitut.

Lins, F. and B. Britzke (2010). Standardisierung und Ergonomie. In Gesellschaft für Arbeitswissenschaft e.V. (Eds.), Menschund prozessorientierte Arbeitsgestaltung im Fahrzeugbau, pp. 29-42. GfA-Press, Dortmund.

Löwe, K. (2007). Consideration of Human Factors in the General Safety Analysis. In Institution of Chemical Engineers (Eds.), Loss prevention: 12th International Symposium on Loss Prevention and Safety Promotion in the Process Industrie, pp. 1-8. IChemE, Rugby, Warwickshire.

Lolling, A. (2003). Analyse der menschlichen Zuverlässigkeit bei Kommissioniertätigkeiten. Shaker, Aachen.

Lotter, E. and U. Müller (2018). Moderne/smarte Montagearbeitsplätze im Umfeld der Industrie 4.0. In R. M. Wagner (Eds.), Industrie 4.0 für die Praxis. Springer, Berlin, Heidelberg.

Lotter, B., J. Hartung, and H.-P. Wiendahl (2012). Altersneutrale Montagegestaltung. In: B. Lotter and H.-P. Wiendahl (Eds.), Montage in der industriellen Produktion. Ein Handbuch für die Praxis, pp. 49-441. Springer, Berlin, Heidelberg.

Mosleh, A. and Y. H. Chang (2004). Model-based human reliability analysis. prospects and requirements. Reliability Engineering \& System Safety 83 (2), 241-253.

Neuhaus, R. (2018). Erst Lean-Management, dann Industrie 4.0!, in Wagner, Rainer Maria (Eds.), Industrie 4.0 für die Praxis. Springer, Berlin, Heidelberg.
Steinberg, U. (2012). Leitmerkmalmethode Manuelle Arbeitsprozesse 2011. Bericht über die Erprobung, Validierung und Revision; Forschung Projekt F2195. Bundesanstalt für Arbeitsschutz und Arbeitsmedizin. Dortmund, Berlin.

Swain, A. D. and H. E. Guttmann (1983). Handbook of human-reliability analysis with emphasis on nuclear power plant applications. Final report. NUREG/CR1278. U.S. Nuclear Regulatory Commission, Washington D.C.

VDI (2015). 4006 Part 1. Menschliche Zuverlässigkeit - Ergonomische Forderungen und Methoden der Bewertung. Beuth, Berlin.

VDI (2017). 4006 Part 2. Menschliche Zuverlässigkeit - Methoden zur quantitativen Bewertung menschlicher Zuverlässigkeit. Beuth, Berlin.

Wiendahl, H.-P., J. Reichardt, and P. Nyhuis (2015). Handbook factory planning and design. Springer, Heidelberg.

Zülch, G., J. Krüger, and O. Bongwald (1998). Produktionslogistische Planung von Prüfstrategien. In M. Engeli (Eds.), Simulationstechnik, pp. 371-378. Vdf, Zurich. 